\title{
WHO THE MUSIC INVITES, WHERE IT TAKES THEM
}

\section{Eachan Holloway}

It just was. A jay did thrash

like a tassel of blue

carbon paper on a hammock

between two doors

of the bedroom. It was

at night. The jay tore

off its feathers, down

to the red dust within the chest,

to the song detonating

in the air. It was as if

the chair was bending.

The chair, the house, the window, the neck were bending. Red song, o. Began right here. Began like the drone of teeth on bones scraped clean. Began and finished. My ear was breaking. Who could hear. The two doors opened. One revealed old cyclamen rising in a field, teaching two lovers to dance. The other opened to a beach 
littered with prismatic stones, like lion's eyes still retrieving light.

It finished while beginning.

The bow snapped on the strings, the bow touched down, the strings shone with sound.

It finished. My red mouth, my torn eye, torn body, the torn finger, all torn were no longer torn, but coming alive.

Like a ragged orchid unfolding within a glass bulb, and the bulb shattering, and the torn not torn, and lying there, leaning there, against the wall, against the door. My torn spine filled with wings, was carried into a field, was borne where young coyotes licked infant faces as if smoothing corners on marble and quartz. It began, it began where the fire began, fire is music's weather. It began in the city for a few hours. Even I was carried-to a field, and all my wounds closed. I was watching the cyclamen, they were wrapping my parents for the end of history. 
The infants did not cry; but I could hear the closing of their eyes, I could hear the static of their tangled hair, I could hear the limping dog in the distance, blind, and drunk. The leaves were on fire there. All my wounds did not close. The instrument did not stop, the trees were on fire. The leaves brightened and hissed like inflamed photographs of jewels.

One door opened and the cyclamen rose. There were two of them, lovers, they were ashen, unsmiling. No one had ever loved them. I wished for them to sleep in barbed wire, I wished for the half of a face, nearly as beautiful, that dissolves in the cupped water of a drunk's hands.

The music lured the water over the stones and the eyes closed and the beach slept.

There were two of them. The red song had torn away their flesh, had torn away their bones. I never exactly saw them. I saw the body the song made, when the song ended and then began. I saw the body enter here, a hermaphrodite, 
and cock its head

and grip its neck.

So furious.

As if it could have turned

to see me. It was the face

cupped in a drunk's hands, and the face

cupped in a queen's.

And it did not see me.

And the music slowed, and it turned, the door

closing behind, and

the music ended.

Left me with a beach

beneath crennolated water

as silently, unseen,

cyclamen danced alone. 